\title{
Special Issue: 50 Years of the Journal of Low Temperature Physics (Part II)
}

\author{
Neil Sullivan ${ }^{1} \cdot$ Jukka Pekola $^{2} \cdot$ Paul Leiderer $^{3}$ \\ Accepted: 24 October 2020 / Published online: 8 November 2020 \\ (c) Springer Science+Business Media, LLC, part of Springer Nature 2020
}

This is Part II of the Special Issue of the Journal of Low Temperature Physics to celebrate the 2019 Jubilee anniversary of the Journal. Part I was published in December of last year [1]. The Journal was initially created by John Daunt to publish original scientific contributions from a wide area of low temperature physics, covering fundamental science and technical innovations.

The Journal expanded considerably in the 1990s with the addition of a European editor, and following community pressure started publishing special series such as the Proceedings of the International Symposia of Quantum Fluids and Solids, the Low Temperature Detector Conferences and other topics in emerging areas of low temperature physics. The scope of the journal now encompasses new fields of contemporary physics, including quantum electronics, quantum phase transitions, topological physics, non-conventional superconductivity, low temperature applications to astrophysics, new technical breakthroughs and the thermal properties of matter (conductivity, transport, heat capacity, etc.) at low temperatures. Today the Journal is served by three editors-in-chief: Jukka Pekola handling submissions from Europe, the Russian federation, Africa and the Near East as well as India and Pakistan, Neil Sullivan (University of Florida) for submissions from the Americas and Far Asia (including China and Japan), and Paul Leiderer (University of Konstanz) who oversees final production of publications and the various special series.

Part II of the Jubilee issue includes reviews on thin quantum films, ions in liquid helium, non-equilibrium phenomena in superconductivity, noise in carbon nanotubes, cooling nano-sized devices to ultra-low temperatures and ultra-low temperature noise thermometry.

Neil Sullivan

sullivan@phys.ufl.edu

1 Physics Department, University of Florida, Gainesville, FL 32611-8440, USA

2 Low Temperature Laboratory, School of Science, Aalto University, P.O. Box 1350000076 , Aalto, Finland

3 Department of Physics, University of Konstanz, 78457 Konstanz, Germany 


\section{Reference}

1. P. Leiderer, J. Pekola, N.S. Sullivan, J. Low Temp. Phys. 197, 111-112 (2019)

Publisher's Note Springer Nature remains neutral with regard to jurisdictional claims in published maps and institutional affiliations. 